Article

\title{
Representation and Governance in International Organizations
}

\author{
David P. Rapkin ${ }^{1}$, Jonathan R. Strand ${ }^{2, *}$ and Michael W. Trevathan ${ }^{2}$ \\ ${ }^{1}$ Department of Political Science, University of Nebraska, Lincoln, NE 68588-0328, USA; E-Mail: dprapkin@gmail.com \\ ${ }^{2}$ Department of Political Science, University of Nevada, Las Vegas, NV 89154-5029, USA; \\ E-Mails: strand@unlv.nevada.edu (J.R.S.); trevatha@unlv.nevada.edu (M.W.T.) \\ * Corresponding author
}

Submitted: 28 December 2015 | Accepted: 25 May 2016 | Published: 11 August 2016

\begin{abstract}
What does representation mean when applied to international organizations? While many scholars working on normative questions related to global governance often make use of the concept of representation, few have addressed specifics of applying the concept to the rules and practices by which IOs operate. This article examines representation as a fundamental, albeit often neglected, norm of governance which, if perceived to be deficient or unfair, can interfere with other components of governance, as well as with performance of an organization's core tasks by undermining legitimacy. We argue that the concept of representation has been neglected in the ongoing debates about good governance and democratic deficits within IOs. We aim to correct this by drawing on insights from normative political theory considerations of representation. The article then applies theoretical aspects of representation to the governance of the International Monetary Fund. We determine that subjecting IOs to this kind of conceptual scrutiny highlights important deficiencies in representational practices in global politics. Finally, our conclusion argues scholars of global governance need to address the normative and empirical implications of conceptualizing representation at the supranational level.
\end{abstract}

\section{Keywords}

governance; international organizations; representation; voting

Issue

This article is part of the issue "Supranational Institutions and Governance in an Era of Uncertain Norms", edited by Russell Alan Williams (Memorial University, Canada) and Reeta Tremblay (University of Victoria, Canada).

(C) 2016 by the authors; licensee Cogitatio (Lisbon, Portugal). This article is licensed under a Creative Commons Attribution 4.0 International License (CC BY).

\section{Introduction}

International organizations (IOs) utilize various rules and practices that govern specific internal functions such as making decisions on lending projects. While these rules can be manipulated by powerful states and bypassed for political expediency, they are critical components to an IO's legitimacy. At times, IOs have faced severe criticism and perceptions of bias, unfairness, rigidity and other sources of dissatisfaction with internal governance. The internal governance of an 10 involves such matters as how an organization aggregates the preferences of its hundreds of members to make and implement collective decisions. A lot of at- tention has focused on whether or not the internal governance of an 10 meets certain standards associated with "good governance." This literature has highlighted the real and perceived shortcomings of internal governance using concepts such as democracy, legitimacy, accountability, transparency and, occasionally, representation (Grant \& Keohane, 2005; Woods, 1999, 2000). Democracy, the broadest of these terms, is said to require legitimacy. Accountability, which is also seen as necessary to both democracy and legitimacy, is usually thought to require a large measure of transparency. Representation is sometimes thrown in for good measure, but rarely receives the close scrutiny afforded to the other properties. Whereas these properties 
are rightly conceived as complex, multidimensional and worthy of conceptual explication, representation is usually considered as if it were a plain-language term, with a self-evident meaning, and therefore not in need of systematic conceptualization.

When scholars address representation in IOs, they may refer to the representation of civil society or the representation of states. We concentrate our analysis on the representation of states, although much of what we consider potentially applies to civil society actors too. ${ }^{1}$ We start from the premise that representation is a fundamental norm of IOs' governance which, if perceived by enough members to be deficient or unfair, can interfere with the other components of governance, as well as with the performance of core tasks. Flawed representation undermines process legitimacy, i.e., the belief of members that the procedures by which the organization's rules and norms are made and enforced are fair, consistent, and thereby deserving of compliance. If representation is seen as flawed, biased and illegitimate, then the rest of the IO's decisions are likely to be regarded as the outcome of a process that itself lacks legitimacy and is not worthy of prima facie compliance. As Plotke (1997, p. 27) emphatically puts it (in a non-IO context), "representation is democracy," in the sense that, "it is crucial in constituting democratic practices." Without perceptions of fair representation, governance reforms to improve accountability or democratic decision-making are suspect, and decisions relating to effective performance of functional missions may also be viewed as inherently biased.

Before addressing the state of representation in IOs we first examine how the concept of representation has developed in the literature and how application of this concept might illuminate the representational practices of IOs. Conceptually, we posit that 10 decision-making comprises a two-stage process. In the first stage members are assigned respective voices in the form of vote(s). The second stage consists of the translation of votes into seats on an IO's apex body. Although this is not a hard-and-fast distinction, first-stage decisions and procedures tend to be more formal, governed by codified instruments such as treaties. Secondstage decision-making is more opaque and tacit, based on norms and informal practices.

We find that two broad connotations emerge from representation that are especially relevant to IOs. One

\footnotetext{
${ }^{1}$ NGOs and civil society organizations claim a representational role, often via informal venues. These forms of nonterritorial representation will have to be accounted for and incorporated into more state-centric models. For now, however, we choose to work on the conceptual foundations of representation among sovereign states; see Warren and Castiglione (2004). A case can also be made for providing representation to transnational corporations. Other candidates for enfranchisement in IOs include the world's "major cultures, religions, and civilizations" (Thakur, 1999, p. 3).
}

construes representation as something akin to a principal-agent (PA) relationship in which most issues revolve around some aspect of how the principal is represented by the agent in legislative bodies. The other connotation, descriptive (or mirror) representation, is instead concerned with how closely the composition of a legislative body reflects the relevant characteristics (e.g., size, wealth, race, class, gender) of the polity it serves. For example, regionalism is a central organizing principle of the UN System and used to help determine how governments are selected for non-permanent seats on the Security Council.

These two meanings of representation are not readily melded into a single concept, but each has some application to different parts of the complex array of the internal governance of IOs. More specifically, descriptive representation fits well the first-stage processes when member states' votes are allocated, while PA-type representation can be separately applied to the secondstage processes in which members are represented in an IO's apex body. ${ }^{2}$ This article demonstrates that descriptive representation describes only the first-stage representation in IOs. Descriptive representation is not able to account for the wide-variety of ways IOs utilize the outputs from formal, first-stage determination of representation. Future research utilizing the concept of representation in IOs needs to identify this disjuncture between the two forms of representation.

The next section surveys the primary meanings assigned to the concept of representation with reference to IOs. Representation, in our view, is an evolving norm that has been understudied by global governance scholars. Following this we examine the numerous principles IOs have employed to implement descriptive representation. We then apply insights from the conceptual discussion to a single IO: the International Monetary Fund (IMF). Our conclusion points toward areas of future research and challenges others to more closely examine representation in international relations.

\section{Representation}

Over the long period stretching from the classical Greek city-states to seventeenth century Europe, the idea that representative government could substitute for direct forms of democratic participation was not widely regarded as workable or legitimate. Representation, as a way to overcome the limitations posed by scale and distance, was thought to be a decidedly second-best alternative that is unable to satisfy democra-

\footnotetext{
2 Representation on an apex body involves a process that selects members from a more general body to the most important decision-making body and is used by most major IOs; those with weighted voting systems and those with onecountry, one-vote rules.
} 
cy's need for political equality (Dahl, 1989). ${ }^{3}$ But the ascendance of the much larger nation-state form of political organization strained the classical ideal of direct democracy to an extent that, by the early nineteenth century, "it was obvious and unarguable that democracy must be representative" (Dahl, 1989, p. 29). By the end of the 20th century attitudes toward representation had changed 180 degrees: it was now regarded by its advocates as the source of the "moral distinctiveness of modern democracy, and the sign of its superiority to direct democracy" (Kateb, 1992, pp. 36-56). With the proliferation of IOs in the latter half of the twentieth century, representational issues in IOs have joined the longstanding debates over representation in democratic polities, thereby extending the search for ways to overcome the democracy-dampening effects of (global) scale and distance, and to apply, "the logic of equality to a large-scale political system" (Dahl, 1989, p. 215). As noted above, here we are concerned with representation of states in IOs and not with civil society as IOs have formal rules for the representation of states.

\subsection{Representation in Legislative Bodies}

Theories of representation have appropriately focused on the relationship between representatives and the constituents they represent in legislative bodies, and have asked questions, such as, how well are citizens represented by those chosen as their representatives? Do representatives have the a priori authorization of those they represent? What lines of accountability are drawn to ensure that the represented can replace those who do not provide satisfactory representation? Given the numerous avenues of investigation it is no surprise that when the concept of representation is scrutinized, authors add operative adjectives to label specific connotations (Pollak, 2007, pp. 88-89).

Thus, in what Pitkin (1967, p. 145) terms the "central classic controversy," advocates of the delegate interpretation contend that representatives are obligated to act so as to reflect as closely as possible the preferences of those they represent. ${ }^{4}$ The opposing

3 On consideration of applying democratic principles to IOs in general, see Dahl (1999) and Keohane, Macedo and Moravcsik (2009). While they do not devote much space to questions of representation in IOs, the authors demonstrate that domestic democracy is not necessarily weakened by the activities of multilateral institutions; also see Rabkin (1998).

${ }^{4}$ For modern applications, see Eulau and Karps (1977), Young (2000), and Mansbridge (2003). There are also recent studies that conceptualize aspects of representation in IOs. Kuper (2004) extends to IOs the notion of representation as responsiveness; in this formulation, responsive representation results from the activities of two types of agencies-accountability and advocacy - that aggregate and connect constituents' preferences to IO decision mechanisms. Rehfeld (2006) attempts a trustee form of representation views the representative's ideal role as requiring that she exercise her own independent judgment in service of the collectivity's broader interests rather than the narrower preferences or opinions of particular constituents. Another distinction is whether we conceive of representation in terms of the activities (deliberation, decision-making, lawmaking) undertaken by representatives or as representatives collectively "standing for" those they represent either symbolically or in terms of one possible connotation of descriptive representation (Pitkin, 1967).

This emphasis on representation as a kind of principal-agent problem, i.e., on the proper relationship between the representative and the represented, ${ }^{5}$ provides interesting and valuable insights so long as we are concerned with questions of how representation operates in legislative bodies. But it is not as easily applied to other aspects of representation in IOs. Descriptive representation is more than merely the mirroring of the identity and attributes of the represented in the representative. Here we are not so much concerned with the relationship between a particular country (or its citizens) and the individuals that represent it in a given 10 . We are instead more interested in the terms on which member states participate in IOs that are charged with making and implementing collective decisions. To what extent do the institution's procedures impact the distribution of relevant attributes and resources across its members? Do these governance processes encourage or constrain the ability of a particular member's (or subset of members') delegation to articulate its preferences and to influence outcomes? Answers to these questions get at the heart of recent debates about voice reforms in IOs and are not readily answered from a strictly PA approach. PA-type analyses of representation in IOs can be fruitful but they are limited by the fact IOs are not legislative bodies. There is a disconnection between PA-type concepts of representation and their application to IOs when we consider what Dovi (2006, p. 2) terms the four key components of representation:

1. Some party that is representing;

2. Some party that is being represented;

3. Something that is being represented (opinions, perspectives, interests);

general theory of representation that addresses another problem that arises in IOs: how to regard the representativeness of representatives who have come to their position by other than democratic means.

${ }^{5}$ We use the terms principal and agent in a loose sense to categorize a family of approaches to representation. For the application of principal-agent theory to IOs, which posits member states as principals and the international organization as agent, see the selections in Hawkins, Lake, Nielson and Tierney (2006), especially Broz and Hawes (2006) and Gould (2006); see also Brown (2010). 
4. Political context, the setting within which the activity of representation is taking place.

First note that the party that is represented (component 2) differs between the traditional conception of representation and representation within IOs. The former denotation puts individual citizens (or constituencies formed of citizens) in this category, while the latter denotes territorial states as the represented parties. To construe representation in the principal-agent form involves looking at components 1 and 2 and the relationship between them. Institutional contextincluding such structural features as methods of forming constituencies, proportional representation, one country/one vote, weighted voting, special majorities -is relevant to all varieties of representation. Most of the literature on representation entails consideration of all four components, with an emphasis on 1 and 2. If, however, we are interested in representation in IOs, component 1 becomes less important and attention is shifted to how components 2 and 3 interact with component 4. Despite the limitations of PA-type approaches, we are not ready to throw the baby out with the bathwater since they may prove to have utility in consideration of second-stage representation.

In sum, we contend that what Pitkin (1967) called descriptive representation is more suitable to questions of first-stage representation in IOs while PA-type analyses may have merit in second-stage considerations of representation.

\subsection{Descriptive Representation}

In descriptive representation, "a representative body is distinguished by an accurate correspondence or resemblance to what it represents, by reflecting without distortion" (Pitkin, 1967, p. 60). Knight's (2002, p. 24) approach to the representativeness of the UN Security Council as an "apex body" ${ }^{6}$ designates what is meant by descriptive representation: "For an apex body to be representative of the broader membership in an organization it must portray the values of the larger group; present the ideas or views of that group; be typical of that group's geographical make-up, population base, and political views; and act as a delegate of that group."

The descriptive representativeness of an 10 depends on how the characteristics Knight proposes are filtered through its system of governance. Rogowski (1981, pp. 398-399) refers to this as an institution's agreed social decision function. How accurately do the prevailing governance procedures of an 10 produce a kind of "picture or map or mirror or sample" (Pitkin, 1967, p. 75)? For any given member, is its representa-

\footnotetext{
${ }^{6}$ Additionally, the Executive Boards of the IMF and World Bank can be thought of as apex bodies in relation to the membership of these IOs.
}

tion comparable to that of other members of like size, contributions, or attributes? The representational criteria Rogowski (1981) suggests tap into what is meant by descriptive representation in relation to how closely an 10 reflects the characteristics of its member states. Is a given member represented fairly in the sense, "that its actual power corresponds to its ostensible power" under these rules? Are its preferences equally weighted, i.e., do they "count" the same as any other member's? And, do members of like capacities enjoy equally powerful representation in that their preferences are equally likely to influence outcomes. The first of these, fairness (as indicated by correspondence of actual and ostensible power) is directly pertinent to the weighted voting systems used by many IOs.

Cogan's (2009, p. 219) notion of an “[o]perational constitution-the combination of formal and informal rules that together regulate how international agreements are made and applied," connotes much the same meaning as Rogowski's agreed social decision function. In Cogan's formulation, representation is implemented in several constitutive processes of IOs: "The election of states to exclusive decision-making bodies; the relative voting weights assigned to states; the election and appointment of individuals of particular nationalities to high- and mid-level offices in IOs; and the de facto devolution of appointment authority for such offices to particular states or groups of states." Assessments of whether a member (or group of members) of a particular IO is fairly represented; or over- or under-represented; or how accurately an IO in the aggregate "mirrors" the distribution of relative attributes across its members all depend on the prior understanding of that IO's institutional context.

Our brief survey of the literature on representation reveals two main connotations that are useful in application to IOs. Most conceptions of representation focus on the relationship between the individual representative and the constituents she represents. We will suggest a role for this approach in application to the second stage of 10 decision making. The other is descriptive representation, which focuses on the extent to which an 10 reflects the composition of the international system within which it operates. This variant of the concept provides a better fit with what most observers mean when referring to representation in IOs. Descriptive representation can be based on a variety of principles and is a useful concept for assessing how closely an 10 follows its specified representational principles in the process that determines the voice of members.

\section{Representational Principles for International Organizations}

Some standards are needed to assess descriptive representation to provide benchmarks against which the 
terms of members' participation can be indexed and compared. Here it is useful to think in terms of a combination of representational principles (Underhill, 2007) because it is unlikely that any one, serving by itself, will capture the complexities of institutional context in IOs. What principles are used in IOs and how might they be augmented by new ones? In other words, representational decisions are a fundamental part of how IOs organize members (Cox \& Jacobson, 1974 , p. 9). We consider geopolitical representation, regional representation, the role of population in determining representation, whether votes are weighted or unweighted, the capacity of members to contribute to an IO's missions, representation of non-state actors, and the representation of weaker members.

\subsection{Geopolitical Representation}

In the UN Security Council (UNSC) context, Knight (2002, p. 25) makes the case for geopolitical representation, defined in terms of more balanced participation along a North-South axis, and requiring that more permanent or non-permanent UNSC seats be assigned to developing countries. Much the same cleavage prevails in other IOs, such as in the World Bank's IDA where there is a division of seats between the wealthier shareholders who do not use facilities and their poorer counterparts who do; this has been a longstanding fault line in global governance. This is the key representation grievance contested in many IOs involved in development policy and reform proposals typically call for providing more voice for developing countries vis-à-vis their lender counterparts. The World Bank's recent voice reforms, for instance, resulted in major changes in the absolute number of votes for many emerging market economies, although this did not result in shifting the relative shares of votes in their favor (Strand \& Trevathan, 2016; Vestergaard \& Wade, 2013). In sum, there are long-established practices using geopolitical factors in descriptive representation.

\subsection{Regional Representation}

Gaining legitimacy during a period of widespread decolonization, the representation of geographical regions has been well-entrenched in the post-WWII international order, particularly in the UN. This principle overlaps considerably with Knight's geopolitical variant. An example of dissent over regional representation is the near consensus among those who follow the IMF that Europe is significantly over-represented in terms of both votes and Executive Board seats at the expense of emerging market governments in Asia and Africa (Rapkin \& Strand, 2005). Moreover, this assessment of regional imbalances holds for virtually any representational principles one might apply. Others who argue that regions are of diminished importance to representation point out that regions are malleable entities and that regionalism is a subjective construct based on sentiment as much or more as on geography. From this standpoint, questions arise about whether geographic regions, especially outside of Europe, are actually a "unit of cohesion" (Thakur, 1999, p. 9) or "simply a convenient way of organizing the world for electoral purposes" (Agam, 1999, p. 42). Regardless of which view one takes, there are examples of IOs using regional distribution rules. The regional development banks (RDBs) take geopolitical representation into account as they bifurcate membership into regional and non-regional members, often with complex rules on the relative shares held by each (Strand, 2014). For instance, in the Inter-American Development Bank, the U.S. and Canada are guaranteed a minimum share of votes (30 percent and 4 percent respectively) and regional borrowers are guaranteed a collective share of 50.005 percent (Strand, 2003).

\subsection{One-Country/One-Vote}

The sovereign equality of states principle is employed in some IOs, such as the UN General Assembly (UNGA) and the World Trade Organization (WTO). The general criticism of this representational principle, often raised in reference to the UNGA, is that the larger and more powerful members will not cede decisive power-overoutcomes to smaller, less powerful members, and that the former therefore make certain that no matter of any consequence is determined by the one-country/ one-vote rule. For other IOs, there is not universal reliance upon a system of weighted voting as many consider it too closely resembling the shareholder model characteristic of corporate governance. Hence, with a nod toward the sovereign equality of states, a number of "basic votes" are allocated to each member. Basic votes can be viewed as contributing to minority representation (see below) but for the most part they are only symbolically important in vote allocation.

\subsection{Representation by Population}

Another principle is the familiar and conceptually simple one-person/one-vote rule, behind which stands much liberal democratic practice. Proposals to implement this principle internationally have predictably run aground of great powers' unwillingness to concede majority control in IOs to more populous "lesser" powers. In recent years, however, the emergence of more powerful and highly populated China and India blur this distinction in IOs like the IMF and World Bank. Population, however, is rarely mentioned in discussions of IMF and World Bank reforms. Indeed, proposals to take population into account in the determination of votes have been dismissed on grounds that population is not relevant to their missions. There remains, however, a 
modicum of support for inclusion of population (Bryant, 2008, Appendix 1). In the UN, various proposals have been floated to weight votes using population as at least one factor to determine representation (Schwartzberg, 2003; Strand \& Rapkin, 2011). Note that using population to weight votes moves representation by population away from the principle of equality of (state) voters. For IOs to claim any sort of democratic basis it may well prove difficult to continue excluding population, as a strong case can be made that decision-making in the most important IOs should pay heed to the size of a country's population (Mirakhor \& Zaidi, 2006). ${ }^{7}$

\subsection{Weighted Voting}

Weighted voting is a dominant representational principle shaping the distribution of votes in numerous IOs. Borrowed from methods of private corporate governance, it is also known as the shareholder model since each owner of X-number of shares of a firm's stock controls a corresponding number $(X)$ of votes. The basis for weighting the number of shares held is relatively noncontroversial in the corporate governance case, but the shareholder model becomes more problematic when applied to governance of IOs. The fundamental question is what features of members should be used to weight votes? IOs that use weighted voting employ indicators of relative weight in the world economy, as indicated by shares of world product, trade, and reserves, but there are other factors determining the final outcomes of the process (e.g., basic votes, regional distribution rules, political pressure by more powerful governments). Whether these criteria continue to accurately represent the relative importance of countries in the 21 st century is a contested question. The selection of seemingly objective economic criteria is anything but simple or apolitical, as variables as simple as national product can be operationalized in many ways and the choice of measure has voting share distributional consequences. Changes in how the indicators are operationalized can significantly affect the relative distribution of votes. In sum, weighted voting is a common way to account for perceived or real imbalances in the relative importance of members, but there is no truly impartial way to determine relative shares and currently used processes are wrought with political maneuvering by governments looking to manipulate their relative position (Rapkin \& Strand, 2006).

\subsection{Capacity Representation}

Capacity representation refers to the principle that

7 For a quite different general view on the diminished importance of population, see McNicoll's (1999, pp. 411-412) useful discussion of what he terms "demographic inconsequence." those members with the greatest capacity to contribute to the success of the organization's primary missions are entitled to greater representation because they perform "differential responsibilities" (Cogan, 2009 , p. 312). This functionalist principle can be interpreted as a criterion for allocation of seats, e.g., those UN members with the greatest capacity to contribute to peace and security are deserving of seats in the UNSC (Knight, 2002, pp. 26-27). The same kind of standard often arises in the context of what types of capacities should be included in a weighted voting system. In other words, how should capacity be defined and operationalized? Capacity to contribute may vary greatly from one 10 to another as the missions of IOs differ as well as what it means to contribute resources in support of an IO's mission (e.g., financial contributions, technical assistance, peacekeeping personnel, etc.).

\subsection{Stakeholder Representation}

Stakeholder representation refers to the formation of constituencies among members who share interests or functionally-defined roles. This corporatist approach to representation is easiest to implement with multiple majority decision rules. In the Global Environmental Facility, for example, if a consensus decision encompassing donor and recipient countries cannot be reached, the decision rule defaults to a double majority mechanism requiring separate 60 percent majorities of the votes of both donors and recipients. The International Seabed Authority extends further the logic of corporatist representation: successful initiatives must gain the majority approval of four groups of stakeholders: consumers, investors, net exporters, and developing countries. Different kinds of representational problems arise from the increasing number of claims of stakeholder status made by nongovernmental organizations (NGOs). ${ }^{8}$ Yet another example of stakeholder representation is found in the International Coffee Organization where members are separated into coffee importers and coffee exporters with weighted voting within each group and decisions requiring support of both importers and exporters. Extending the concept of stakeholder beyond representatives of governments, to perhaps corporations and civil society organizations, is seen by some as one way to augment global democracy. Such a broad view of stakeholder interests, however, may attenuate the willingness of states to delegate authority to IOs and representation is likely to remain focused on the state (Zürn \& Walter-Drop, 2011, p. 275.). Furthermore, non-state stakeholders in

\footnotetext{
8 See Kahler (2004, pp. 150-154) for a discussion of whether providing representation to causes already likely to be supported by the national governments of wealthier members but opposed by many developing countries provides a kind of representational "double counting."
} 
global governance present an assortment of accountability concerns (Grant \& Keohane, 2005).

\subsection{Minority Representation}

In descriptive representation there are often concerns about the representation of minority positions which may lead to efforts "to prevent possible tyranny of the majority," by "strengthen[ing] representation of the numerically or otherwise weak and to grant them a formal role in decision-making" (Underhill, 2007, p. 8). ${ }^{9}$ Intersecting with the concept of minority representation, as well as with stakeholder representation, is the idea that representation should be provided to those who are most affected by the policies resulting from the decisions of the majority. Protection of minority shareholders' rights is a best-practice benchmark of corporate governance that could also be applied in IOs, primarily by improving accountability and transparency. Many IOs have implemented accountability mechanisms owing in part to these concerns. In decisionmaking, there have been concrete measures proposed to increase minority representation in the executive boards of the Bretton Woods institutions including setting up a committee comprised of minority (debtor) executive directors to audit the activities of the majority and replacing the opaque consensual decisionmaking process with recorded votes. ${ }^{10}$ Moreover, the World Bank recently expanded the number of voting groups dedicated to African governments in order to increase their representation.

\section{Implications of Representative Principles}

Consideration of representational principles reveals two main connotations that are useful in application to IOs. One focuses on the relationship between the individual representative and the constituents she represents (as reflected in the principal-agent formulation applied to second-stage representation). The other is first-stage, descriptive representation, which focuses on the extent to which an 10 reflects the configuration of the international system within which it operates. For many IOs where decisions are made on how to allocate scarce resources, some form of weighted voting seems necessary to provide representation that accommodates disparities in size, power, and systemic importance of states and that is capable of adapting to changes in this composition. In this context, voting systems amount to ongoing experiments in institutional design.

\footnotetext{
${ }^{9}$ See Guinier (1994) and Young (2000) for advocacy of special arrangements to provide minority representation. Phillips (2003) makes a similar argument regarding the exclusion of women from systems of representation.

10 These ideas have been suggested by Marfan (2001). For discussions of Marfan's work, see Kapur and Naim (2005).
}

The above principles are manifest in the representation systems of IOs but there is no systematic, nor in our view straightforward, way to mesh them into a single set of procedures to represent states in IOs. Put differently, there is no ideal system of representation that is technically superior and that all members of IOs agree upon. Not only will any such system be politicized to some degree, it will also be a hybrid in so far as it will necessarily consist of some mix of the above representational principles. This leaves open the possibility that the mix will be a kind of hodge-podge, resulting from lowest-common-denominator compromises and from the preferences of the most powerful members. Nevertheless, we next turn to a brief sketch of key rules and practices that constitute the two forms of representation to a single institutional context: the IMF. ${ }^{11}$

\subsection{Application of Representation Principles}

In order to focus our discussion, we first examine vote determination in the IMF. The authority of the IMF has waxed and waned over the last several decades. From a pivotal position in the development discourse as purveyor of the Washington Consensus and enforcer of neoliberalism, the Fund's influence diminished in the face of widespread dissatisfaction with its performance, especially since meeting its "Stalingrad" in the form of the East Asian financial crisis in the late 1990's. By the middle of the first decade of the $21^{\text {st }}$ century, numerous journalistic articles, academic papers, and NGO reports described an IMF wracked by crises of confidence, identity, credibility, budget, role or purpose, and/or legitimacy, some of which, singly or in combination, were said to constitute an existential crisis. Its outstanding loans shrank, debtor countries paid their IMF loans early, and the number of borrowers seeking new loans diminished. During the same period, major economies in East Asia began to explore institutional alternatives by entering into currency swap arrangements that operate with only modest input from the IMF. The institution came to be described as obsolete, adrift, groping for a mission, and sliding into deserved irrelevance (Griesgraber, 2009; Seabrooke, 2007; Torres, 2007). Then the financial meltdown of 2007-2008 restored the perceived need for the IMF and its crisis management role (Broome, 2010). Resources were again appropriated for the IMF and bailouts of developing countries on the wrong end of payments imbalances proceeded.

Some of the IMF's problems are attributable to changes in the world economy, particularly the availability of alternative sources of finance provided by the rapid expansion of private capital markets, as well as

${ }^{11}$ For more detailed consideration of IMF rules and practices, see Strand (2014), Rapkin and Strand (2005), and Bryant (2008). 
the emergence of nascent regional and global financial facilities. Yet another source of the Fund's difficulties stems from perceptions of bias, unfairness, rigidity and other sources of dissatisfaction with the IMF's internal governance, that is, how the organization aggregates the preferences of its members to make and implement collective decisions. Most often faulted on this score are perceived shortcomings in democracy, legitimacy, accountability, transparency, and representation.

The IMF is a case where some studies focus only on first-stage concerns while others highlight secondstage issues of representation. While space does not allow for a comparative analysis, we think a focus on the IMF helps illustrate why our distinction between stages of representation is warranted. Applying notions of representation to the IMF is complicated by several features of the IO's governance. First, the representation of members unfolds across two separate, but linked, stages. First-stage representation is reflected in the IMF's complex system of weighted voting, wherein the number of weighted votes assigned to each member is (nearly) proportional to its quota which, in turn, is supposed to be a function of members' relative size in the world economy. The methods by which quotas are determined are in principle objective and replicable, though in practice the process has been opaque at various junctures and has frequently been subject to political interference; perhaps akin to how the voting rights and representation of certain individuals in domestic political systems has been historically disrupted by powerful political forces. Second, first-stage representation provides inputs to the construction of second-stage representation in the IMF's Executive Board (EB). Over the past several years, reforms to IMF governance languished largely due to inaction by the U.S. The reforms include central aspects of representation of states and highlight how concerns about how states are represented in an 10 can undermine the ability of an 10 to carry out its mandates (Seabrooke, 2007). Before moving on, we note that consideration of the two stages of representation applies to other IOs, not just those utilizing weighted voting systems. Most IOs use some form process to select members from a more general body to a smaller body with a lot of authority.

\subsection{First Stage Representation: Determination of Voting Shares}

IMF voting shares are derived from IMF quotas; quotas are often referred to as the "building blocks" of IMF governance and serve multiple purposes in the institution's internal governance regime, including influencing its representation in the EB. Quotas themselves are supposed to reflect countries' relative weight in the international economy, as determined by a set of variables.

General Quota Reviews are undertaken at five-year intervals with the primary purpose of adjusting repre- sentation to reflect changes in members' relative positions in the world economy, as well as accommodating entry of new members, and making various ad hoc adjustments. At least in principle then, representation of governments in the IMF is designed to be flexible and responsive to shifts in the distribution of economic power among its members. To be sure, political leverage has been exercised by the major creditors at various points in the vote determination process. Moreover, reasonable observers disagree about whether the quota regime has inflated the quotas of the developed countries at expense of debtor countries' quotas. This issue entails consideration of the effects of the choice of variables, weights, and formulas used to determine quotas.

Until 2008, quotas were derived from, but not strictly determined by, a complex system of five formulas based on GDP, the values and variability of receipts (exports), payments (imports), and international reserves. We concur with Bryant's (2008, p. 2) contention that, "adopting a better formula [consisting of the variables chosen, their measurement, and how they are weighted] is the single most important requirement for successful governance reform for the IMF." Given their building block function, it is especially important that quotas be determined by a process that is regarded as transparent and fair (Bird \& Rowlands, 2006). But no clear, persuasive rationale has ever been provided for the original set of variables included, the weights assigned to them, or the distributive outcomes produced. It is clear that these aspects of vote determination procedures were thoroughly politicized from the outset and that particular principles behind quotas were adopted out of political expediency. In 2008, reforms were introduced including the move to a single formula. The new formula includes GDP, a five-year moving average of payments and receipts, the variability of current receipts and capital flows, and reserves. Share of global product is comprised of PPP-GDP and market exchange rate GDP and the variable is weighted to account for half of members' quotas. Arguably, this simplified formula is an improvement over the previous configuration of five formulas, though it remains awkward and intricate.

The connection between these specific economic variables and the (descriptive) representation of governments in an 10 is not obvious as there are other guiding factors (e.g., capacity to contribute or population) that arguably can be relevant. Principles not incorporated in IMF vote determination tell us a lot about how influential members and dominant ideas about representation lead to the selection of specific principles from a larger set of possible ways to determine representation.

One area in vote determination that suggests attention is paid to stakeholder and minority representation is the allocation of basic votes. In addition to the votes generated by the quota process, each member country 
is assigned basic votes. Until recently, basic votes have amounted to an all-time low of barely more than two percent of the total votes, down from the original 11.3 percent agreed on in 1944 at Bretton Woods and from the historic high in 1958 of 15.6 percent. The 2008 reforms increased basic votes to 5.5 percent. Basic votes result in an increase in the relative voice of those members with very low quotas, but matter little in the representation of large vote holders.

In sum, the determination of voting shares as an exercise in defining the representation of governments in the IMF has, from its inception, often been subject to political manipulation and remains flawed in the ways described, especially the selection of variables, weights, and formula(s). Let us assume for the sake of argument that the vote determination process, the results of which we have termed first-stage representation, yields perfectly formed building blocks that are then used by members as they cast votes. How then does this distribution of votes translate into second stage representation on the EB? And, from a conceptual standpoint, what definition of representation best captures decision making itself?

\subsection{Second Stage Representation: The Executive Board}

Second stage representation involves selective representation whereby most members are aggregated into voting groups for representation on the EB. Members' votes-the product of first stage calculations-are used to form voting groups and to elect representative to the EB. These elected Executive Directors (EDs) decide on the substantive and procedural issues that comprise the business of the IMF. The EB and its constituencies use a consensual decision-making in which informal deliberations often take place outside the designated venues, votes are rarely taken, and representation therefore becomes murky and harder, if not impossible, to directly measure or replicate. Relatively, the determination of votes is transparent when compared to the more opaque and indirect representation on the EB. Descriptive representation does not shed light on second stage decision-making.

We first note that another feature of the IMF's that confounds efforts to assess representation is that there are several informal rules used by the Fund: "Formal rules are...enacted through accepted decision-making processes. Informal rules...do not pass through these processes" (Cogan, 2009, pp. 214-215). "Much of international decision making is done through informal processes...In no area is this more apparent than in the realm of agreements concerning international representation" (Cogan, 2009, p. 227). For example, it is impossible to assess the additional "representation" that has accrued to European members from the longstanding practice that the IMF Managing Director is always a European. Surely this informal convention regu- lating leadership selection has redounded to European advantage in manifold ways. Other informal practices have likewise had significant representational implications such as the selection of staff (Momani, 2007). Accordingly, in the balance of the article we narrow our focus to the formal operation of the EB.

In the EB, three formal rules have consequences for representation. First, the Fund requires the aggregate votes of each constituency be cast as a block. Second, elected EDs are not considered representatives. Third, the EB uses a variety of qualified majorities, which combined with weighted voting underscores the power of the larger vote holders. Formal rules and informal practices used by the EB have a variety of consequences for representation in the Fund. In this section we detail how these rules and practices distort representation principles.

The first response to questions about how first stage results plug into second stage decision making is, as Lombardi $(2009$, p. 16) puts it, that "[t]he distribution of quotas heavily affects the allocation of seats in the...executive board." At its inception, the 39 members of the IMF were served by twelve Executive Directors (EDs), one each for the five largest shareholders and seven others elected by voting groups. Each ED represented, on average, 3.25 members. In consequence of the many new post-colonial members, by 1964 the EB had been expanded to 20 seats (serving a total membership of 93, or 4.65 members each). Subsequent additions-Saudi Arabia (1978), China (1980), Russia and others (1990-1992)-increased the EB to twenty-four. The Board is currently comprised of seven singlemember chairs: an ED appointed by each of the five largest shareholders, and one each from Saudi Arabia and Russia. EDs from the five largest shareholders are appointed for an indefinite term. Elected EDs serve a two-year term which, according to some observers, "is too short...to master all the complexities of IMF operations, to establish productive relations with management, the staff and fellow directors and to become fully effective" (Portugal, 2005, p. 79). The resulting differences in experience and learning are manifest in disparities in the ability, "to develop institutional memories and expertise in how to function in the IMF...to negotiate effectively and to shape the issues and decisions around which the consensus must form" (Bradley, 2006, p. 11).

Elected EDs generally are the members with the most votes within their voting groups. This artifact of group formation magnifies the distribution of votes that emerges from the first stage process so that creditors control EB seats. Not only is there is a strong tendency for the members with the most votes to control voting groups, but EDs cast the total voting weights held by all members in its voting group as a bloc. ${ }^{12}$ The

12 See Strand and Retzl (2016) for analysis of selective representation and voting groups in the World Bank. 
absurdity of these arrangements from a representational standpoint is obvious when one considers that members of the same constituency have at times been engaged in conflict yet their votes were cast by their ED as a bloc. Once elected, an ED can only be replaced at the time of the next election. As Woods \& Lombardi (2006, p. 10) point out, any borrower country strategy that relies on, "[j]oining forces with one another does not give them adequate voting power to set or influence the agenda." This constraint is made even more binding by the prohibition on splitting the votes of constituencies even when members within a constituency have major disagreements. As Martinez-Diaz (2009, p. $397)$ concludes "the voice and voting power of small shareholders is diluted in multi-country constituencies." Notably, recent reforms will change the current system of ED selection to one where all EDs will be elected. The fact that an ED has been elected by the other members in his voting group, according to Gianviti, (1999, p. 48), "does not create an obligation for him to defer to their views or to cast their votes in accordance with their instructions." These restrictive decision rules magnify the power over outcomes of lending countries while reducing that of borrowing countries. For those developing countries which are members of mixed constituencies their votes are in effect a kind of "dead wood," unable to be mobilized for building coalitions supportive of borrower interests with other developing countries. Worse yet, they can be deployed by the mixed constituency EDs in support of initiatives that favor creditor interests. In this fashion, the composition of the EB and its particular form of consensus decision making combine to strengthen the representation of developed countries beyond that already reflected in their sizeable majority of votes. As a corollary, whatever representation is indicated by developing country shares of votes is discounted and deeply distorted by the EB's consensual decision rules. Undercutting any notion of representation is the simple fact the current process does not provide mechanisms by which an elected ED can be held accountable to other members of his or her constituency.

IMF governance reforms agreed to in 2008 and 2010 tinkered with the representation of members but did not result in major realignments (Lesage, Debaere, Dierckx, \& Vermeiren, 2013; Wade \& Vestergaard, 2015). ${ }^{13}$ Dissatisfaction with representational outcomes of the reforms contributed to the U.S. delay in approving the 2010 reforms. Changes to how representational principles are operationalized in the IMF that

13 In the context of a legitimacy maintenance strategy, Guastaferro and Moschella (2012) consider the IMF's 2010 reforms as part of the Fund's "representative turn." In our context here, however, the reforms fail to fundamentally change the conceptual and practical divide between descriptive representation and second-stage representation. are part of the 2010 reforms were effectively blocked for years since the U.S. holds a de facto veto. Now that reforms are approved, we note that they primarily address first-stage representation and do little to ameliorate problems with second-stage representation in IMF.

\section{Conclusions}

We argue that the concept of descriptive representation fits reasonably well the process of first-stage representation in IOs. Though imperfect, the vote-determination process allows agreed upon representational principles to be operationalized to establish members' voices, influence, and votes as an exercise in representation. Descriptive representation, however, is not very useful to understanding second stage representation in IOs. Further analysis is needed to determine if there is a PAtype of representation that applies and helps to understand second-stage representation. Such an approach can analyze the relationship between the representative and her constituents and address traditional questions such as: how well does a representative represent her constituents: As a delegate or a trustee? Is she responsive to constituency preferences? Is she an effective advocate? Is she accountable (and to whom)? In theory such an approach to second stage representation could address these questions about representation in an 10 setting. In our brief case on the IMF, however, the representational practices employed at the second-stage garbles the inputs from the first stage to a point where the concept may cease to be valuable. Application of our approach to other IOs can help shed light on how informal processes clash with formal arrangements as they do in the IMF.

In other words, what kind of representation:

- Exists when the 10 itself eschews the term representation and expressly denies that EDs are representatives of their voting groups?

- Heightens the biased distribution of votes that emerges from the first stage determination process so that creditors control even more seats on the apex body?

- Allows EB matters to be decided in extrainstitutional venues by subsets of members?

- Does not always permit small country representatives to play a role in formulation of their constituencies' policy positions?

- Licenses representatives (i.e., EDs) to ignore the interests of those who elected them by allowing representatives to cast constituents' own votes against their expressed preferences?

- Does not provide mechanisms by which EDs can be held accountable to voting group members for their performance?

The point is not that all decision-making tramples 
on the norm of representation in the various ways described in the worst practices catalog we have assembled from the case on the IMF. But for those who are concerned with questions of whether global democracy is possible in IOs, the IMF case offers mixed lessons. Even if vote determination were perfectly aligned with members' expectations of what principles representation should be based on, the aggregation of members into voting groups stretches even the most elastic definition of representation into an unrecognizable set of processes that may undermine legitimacy of the $I 0$. The IMF case illustrates the pathologies that can ensue when the second stage processes are divorced from descriptive representation.

We launched into this article to challenge others to deal more directly with representation in global governance. The two principal connotations of representation do fit IOs but in an inelegant, indeed awkward, way. The first stage is best construed as descriptive representation in which the objective is for the distribution of votes to mirror as closely as possible the core representation principles used by the 10 . The second stage encompasses various formal and informal decision rules that use the first stage representational outputs to arrive at decisions. Instead of descriptive representation the more common view of representation involving principals and agents is germane to the operation of IOs. At present, these two formulations are simply juxtaposed and not easily melded into a single, comprehensive concept of representation. Despite the awkward fit, we did find that subjecting one 10 to this kind of conceptual scrutiny highlights important deficiencies in its representational practices. We believe similar results will be found in other IOs. Clearly the concept of representation needs to be incorporated into the more general discourse about institutional design and the possibility of democratic values in IOs.

\section{Acknowledgements}

Earlier versions of this paper received useful comments from several people including Irfan Nooruddin. Four anonymous referees were instrumental in improving this work.

\section{Conflict of Interests}

The authors declare no conflict of interests.

\section{References}

Agam, H. (1999). Equitable geographic representation in the twenty-first century. In R. Thakur (Ed.), What is equitable geographic representation in the twentyfirst century? (pp. 40-46). New York, NY: The United Nations University Press.

Bird, G., \& Rowlands, D. (2006). IMF quotas: Construct- ing an international organization using inferior building blocks. Review of International Organization, 1, 153-171.

Bradley, D. D. (2006). The governance of the IMF: The need for comprehensive reform. Paper prepared for the meeting of the G24 technical committee, Singapore.

Broome, A. (2010). The International Monetary Fund, crisis management and the credit crunch. Australian Journal of International Affairs, 64(1), 37-54.

Brown, R. L. (2010). Measuring delegation. Review of International Organizations, 5(2), 141-175.

Broz, J. L., \& Hawes, M. B. (2006). US domestic politics and International Monetary Fund Policy. In D. G. Hawkins, D. A. Lake, D. L. Nielson, \& M. J. Tierney (Eds.), Delegation and agency in international organizations (pp. 41-76). New York, NY: Cambridge University Press.

Bryant, R. (2008). Reform of quota and voting shares in the International Monetary Fund: 'Nothing' is temporarily preferable to an inadequate 'something'. Washington, DC: Brookings Institution.

Cogan, J. K. (2009). Representation and power in international organization: The operational constitution and its critics. American Journal of International Law, 103(2), 209-263.

Cox, R. W., \& Jacobson, H. K. (1974). The framework for inquiry. In R. W. Cox \& H. K. Jacobson (Eds.), The anatomy of influence: Decision making in international organization (pp. 1-36). New Haven: Yale University Press.

Dahl, R. A. (1989). Democracy and its critics. New Haven, CT: Yale University Press.

Dahl, R. A. (1999). Can international organizations be democratic? A skeptic's view. In I. Shapiro \& C. Hacker-Cordon (Eds.), Democracy's edges (pp. 19-36). Cambridge: Cambridge University Press.

Dovi, S. (2006). Political representation. The Stanford Encyclopedia of Philosophy. Retrieved from http:// plato.stanford.edu/entries/political-representation

Eulau, H., \& Karps, P. D. (1977). The puzzle of representation; specifying components of responsiveness. Legislative Studies Quarterly, 2(3), 233-254.

Gianviti, F. (1999). Decision making in the International Monetary Fund. In International Monetary Fund (Ed.), Current developments in monetary and financial law, Vol. 1 (pp. 31-67). Washington, DC: International Monetary Fund.

Gould, E. R. (2006). Money talks: The International Monetary Fund, conditionality, and supplementary financiers. Stanford: Stanford University Press.

Grant, R. W., \& Keohane, R. O. (2005). Accountability and abuses of power in world politics. American Political Science Review, 99(1), 29-43.

Griesgraber, J. M. (2009). Reforms for major new roles of the International Monetary Fund? The IMF post-G20 summit. Global Governance, 15(2), 179-185. 
Guastaferro, B., \& Moschella, M. (2012). The EU, the IMF, and the representative turn: Addressing the challenge of legitimacy. Swiss Political Science Review, 18(2), 199-219.

Guinier, L. (1994). The tyranny of the majority: Fundamental fairness in representative democracy. New York, NY: Free Press.

Hawkins, D. G., Lake, D. A., Nielson, D. L., \& Tierney, M. J. (2006). Delegation and agency in international organizations. New York: Cambridge University Press.

Kahler, M. (2004). Defining accountability up: The global economic multilaterals. Government and Opposition, 39(2), 132-158.

Kapur, D., \& Naim, M. (2005). The IMF and democratic governance. Journal of Democracy, 16(1), 89-102.

Kateb, G. (1992). The inner ocean: Individualism and democratic culture. Ithaca, NY: Cornell University Press.

Keohane, R. O., Macedo, S., \& Moravcsik, A. (2009). Democracy-enhancing multilateralism. International Organization, 63(1), 1-31.

Knight, W. A. (2002). The future of the UN Security Council: Questions of legitimacy and reputation in multilateral governance. In A. F. Cooper, J. English, \& R. Thakur (Eds.), Enhancing global governance: Towards a new diplomacy (pp. 19-37). Tokyo: United Nations University Press.

Kuper, A. (2004). Democracy beyond borders: Justice and representation in global institutions. Oxford, UK: Oxford University Press.

Lesage, D., Debaere, P., Dierckx, S., \& Vermeiren, M. (2013). IMF reform after the crisis. International Politics, 50(4), 553-578.

Lombardi, D. (2009). Report on the civil society (fourth pillar) consultations with the International Monetary Fund on reform of IMF governance. Washington, DC: New Rules for Global Finance.

Mansbridge, J. (2003). Rethinking representation. American Political Science Review, 97(4), 415-428.

Marfan, M. (2001). Globalizacion y go bernabilidad (ECLAC Working Paper). Santiago, Chile: Economic Commission for Latin America and the Caribbean (ECLAC).

Martinez-Diaz, L. (2009). Boards of directors in international organizations: A framework for understanding the dilemmas of institutional design. Review of International Organizations, 4(4), 383-406.

McNicoll, G. (1999). Population weights in the international order. Population and Development Review, 25(3), 411-442.

Mirakhor, A., \& Zaidi, I. (2006). Rethinking the governance of the International Monetary Fund (IMF Working Paper WP/06/273, December). Washington, DC: International Monetary Fund.

Momani, B. (2007). Another seat at the board: Russia's IMF executive director. International Journal, 62(4), 916-939.
Phillips, A. (2003). The representation of women. In R. A. Dahl, I. Shapiro, \& J. A. Cheibub (Eds.), The democracy sourcebook (pp. 354-364). Cambridge, MA: MIT Press.

Pitkin, H. F. (1967). The concept of representation. Berkeley, CA: University of California Press.

Plotke, D. (1997). Representation is democracy. Constellations, 4(1), 19-34.

Pollak, J. (2007). Contested meanings of representation. Comparative European Politics, 5, 87-103.

Portugal, M. (2005). Improving IMF governance and increasing the influence of developing countries in IMF decision-making. In A. Buira (Ed.), Reforming the governance of the IMF and World Bank (pp. 76-106). London: Anthem Press.

Rabkin, J. A. (1998). Why sovereignty matters. Washington, DC: American Enterprise Institute Press.

Rapkin, D. P., \& Strand, J. R. (2005). Developing country representation and governance of the International Monetary Fund. World Development, 33(12), 19932011.

Rapkin, D. P., \& Strand, J. R. (2006). Reforming the IMF's weighted voting system. The World Economy, 29(3), 305-324.

Rehfeld, A. (2005). The concept of constituency: Political representation, democratic legitimacy, and institutional design. Cambridge, UK: Cambridge University Press.

Rogowski, R. (1981). Representation in political theory and in law. Ethics, 91(3), 395-430.

Schwartzberg, J. E. (2003). Entitlement quotients as a vehicle for United Nations reform. Global Governance, 9, 81-114.

Seabrooke, L. (2007). Legitimacy gaps in the world economy: Explaining the sources of the IMF's legitimacy crisis. International Politics, 44, 250-268.

Strand, J. R. (2003). Measuring voting power in an international institution: The United States and the InterAmerican Development Bank. Economics of Governance, 4(1), 19-36.

Strand, J. R. (2014). The International Monetary Fund. In L. Levi, G. Finizio, \& N. Vallinoto (Eds.), The democratization of international organizations (pp. 94-108). London: Routledge.

Strand, J. R., \& Rapkin, D. P. (2011). Weighted voting in the United Nations Security Council: A simulation. Simulation \& Gaming, 42(6), 772-802.

Strand, J. R., \& Retzl, K. J. (2016). Did recent voice reforms improve good governance within the World Bank? Development and Change, 47(3), 415-445.

Strand, J. R., \& Trevathan, M. W. (2016). Implications of accommodating rising powers for the regional development banks. In S. Park \& J. R. Strand (Eds.), Global economic governance and the development practices of the multilateral development banks (pp. 121-142). London and New York: Routledge.

Thakur, R. (1999). UN electoral groupings reform. In R. 
Thakur (Ed.), What is equitable geographic representation in the twenty-first century? (pp. 1-10). New York: The United Nations University.

Torres, H. R. (2007). Reforming the International Monetary Fund: Why its legitimacy is at stake. Journal of International Economic Law, 10(3), 443-460.

Underhill, G. R. D. (2007). Global financial architecture, legitimacy, and representation: voice for emerging markets (GARNET Policy Brief 3). France: GARNET/CERI Institut d'Etudes Politiques.

Vestergaard, J., \& Wade, R. H. (2013). Protecting power: How Western states retain the dominant voice in the World Bank's governance. World Development, 46, 153-164.

Wade, R. H., \& Vestergaard, J. (2015). Why is the IMF at an impasse, and what can be done about it? Global Policy, 6(3), 290-296.

Warren, M., \& Castiglione, D. (2004). The transformation of democratic representation. Democracy and Society, 2(1), 19-22.

Woods, N. (1999). Good governance in international organizations. Global Governance, 5(1), 39-61.

Woods, N. (2000). The challenge of good governance for the IMF and the World Bank themselves. World Development, 28(5), 823-841.

Woods, N., \& Lombardi, D. (2006). Uneven patterns of governance: How developing countries are represented in the IMF. Review of International Political Economy, 13(3), 480-515.

Young, I. M. (2000). Inclusion and democracy. Oxford, UK: Oxford University Press.

Zürn, M., \& Walter-Drop, G. (2011). Democracy and representation beyond the nation state. In S. Alonso, J. Keane, \& W. Merkel (Eds.), The future of representative democracy (pp. 258-281). Cambridge: Cambridge University Press.

\section{About the Authors}

David P. Rapkin is emeritus associate professor of political science at the University of Nebraska. He has published widely on numerous topics in international political economy. His recent work includes Transition Scenarios: China and the United States in the Twenty-First Century with William R. Thompson (University of Chicago, 2013).

Jonathan R. Strand is professor of political science at the University of Nevada, Las Vegas. His research focuses on global economic governance and international relations of the Asia-Pacific region. His research has appeared in World Development, Development and Change, Foreign Policy Analysis, the Journal of East Asian Studies and elsewhere. In 2016 he co-edited, with Susan Park, Global Economic Governance and the Development Practices of the Multilateral Development Banks (Routledge).

Michael W. Trevathan is a Ph.D. student in the Department of Political Science at the University of Nevada, Las Vegas and is an instructor at the University of West Florida. His research interests include international political economy, global economic governance, natural resource politics, and the economic and security implications of great power transitions. 